\title{
François Ost: de un Kelsen jupiterino a un Hermes ¿democrático? Sobre la dinámica y la mediación. Una contraposición hegeliana
}

\author{
François Ost: from a Jupiterian Kelsen to a 'democratic'(?) Hermes. On \\ Dynamics and Mediation. A Hegelian Opposition
}

\author{
Por: Herszenbaun, Miguel* \\ UNIPE-CONICET/UBA \\ Buenos Aires, Argentina
}

Email: herszen@hotmail.com

Fecha de recepción: 03/08/2021

Fecha de aprobación: 28/09/2021

DOI: https://doi.org/10.30972/nvt.1725714

\section{Resumen}

El presente trabajo se propone discutir dos de los modelos de juez propuestos por François Ost: Júpiter y Hermes. Según Ost, Júpiter puede representar tanto el positivismo jurídico de Kelsen como el iusnaturalismo. En este sentido, intentaré demostrar que la caracterización que Ost hace de Kelsen es parcial. Se limita a considerar la estática del Derecho pasando por alto los rasgos de la dinámica jurídica de Kelsen. A su vez, demostraré los límites de la equiparación entre positivismo y iusnaturalismo. En cuanto al juez Hermes, Ost le atribuye un carácter democrático sostenido en aspectos formales y procedimentales del Derecho, así como en la libertad de expresión. A pesar de esto, me propongo demostrar que Hermes se caracteriza por un rasgo potencialmente antidemocrático: la decisión judicial es, a pesar de sus apariencias, inmediata y sostenida en una intuición moral. Esto supone en la función

\footnotetext{
* Doctor en filosofía (UBA), abogado (UBA) y profesor de filosofía (UBA). Investigador asistente del CONICET. Docente de la Facultad de Derecho y Facultad de Filosofía y Letras. Publicó el libro La antinomia de la razón pura en Kant y Hegel (Alamanda, 2018). Entre sus publicaciones se destacan: "La lectura hegeliana de la apercepción trascendental kantiana como una crítica y reelaboración de la lógica trascendental de Kant" (Con-textos Kantianos, 2018) y "La lectura hegeliana de la Antinomia de la razón pura" (Ideas y valores. Revista colombiana de filosofía, 2017).
} 
judicial hermética un rasgo unilateral, parcial y antidemocrático. Finalmente, concluiré mi trabajo contraponiendo la figura hermética a la mediación hegeliana. Aunque no me propongo desarrollar la filosofía jurídico-política hegeliana, sí intentaré mostrar cómo la noción de mediación está presente en el pensamiento práctico de Hegel y cómo puede ser una respuesta a las insuficiencias de Hermes.

\section{Palabras clave: Ost - Kelsen - Hegel - Estática - Dinámica - Mediación}

\section{Abstract}

In this paper, I intend to discuss two models of judge proposed by François Ost: Jupiter and Hermes. According to Ost, Jupiter represents both Kelsen's positivism and iusnaturalism. In what follows, I intend to prove that Ost's characterization of Kelsen is partial. It is restricted to consider the static character of his theory omitting Kelsen's legal dynamics. Besides, I will show the limits of Ost's equation between positivism and iusnaturalism. In regard to Hermes, Ost claims that it has a democratic character due to formal aspects of Law and its process and to freedom of speech. However, I intend to prove that Hermes is strongly anti-democratic: the ruling es immediate and based on a moral intuition. This implies that it is unilateral, partial, and antidemocratic. Finally, I will contrast Hermes with Hegel's concept of mediation. I do not intend to fully discuss Hegel's political and legal philosophy, but I do intend to show that Hegel's concept of mediation can provide an answer to Hermes' deficiencies.

$$
\text { Keywords: Ost - Kelsen - Hegel - Statics - Dynamics - Mediation }
$$

\section{Cómo citar este artículo:}

APA: Herszenbaun, M. (2021). François Ost: de un Kelsen jupiterino a un Hermes ¿democrático? Sobre la dinámica y la mediación. Una contraposición hegeliana. Nuevo Itinerario, 17 (2), 66-96. Recuperado de: (agregar dirección web) 
François Ost: de un Kelsen jupiterino a un Hermes ¿democrático?

Sobre la dinámica y la mediación. Una contraposición hegeliana

\section{I- Introducción}

En el presente trabajo me propongo discutir los modelos de los jueces Júpiter y Hermes propuestos por Ost. Con respecto al modelo del juez Júpiter, mostraré que Ost se ocupa únicamente de una faceta del pensamiento kelseniano, i.e. la estática del Derecho, desconociendo los rasgos particulares de la dinámica jurídica concebida por Kelsen. Por otra parte, la propuesta jurídica de Ost, plasmada en la figura del juez Hermes, supone una reivindicación y particular concepción de lo democrático. En este sentido, me propongo discutir las tesis centrales de Ost a fin de demostrar que su concepción de lo jurídico resulta antidemocrática. Señalaré el carácter inmediato de la solución jurídica creada por Hermes. Esto implicará la faceta unilateral, parcial y potencialmente antidemocrática de Hermes. Finalmente, concluiré mi trabajo contraponiendo la figura hermética a la mediación hegeliana. Aunque no me propongo desarrollar la filosofía jurídico-política hegeliana, sí intentaré mostrar cómo la noción de mediación está presente en el pensamiento práctico de Hegel y cómo puede ser una respuesta a las insuficiencias de Hermes.

\section{II- Los modelos de juez de François Ost. Kelsen, ¿jupiterino? Hermes, ¿demócrata?}

En “Júpiter, Hércules, Hermes. Tres modelos de juez" François Ost presenta tres paradigmas para concebir el accionar judicial. Cada uno de estos modelos se corresponde a su vez con una cierta concepción del Derecho y del Estado, un período histórico y una escuela filosófica. En esta sección quisiéramos analizar las tres figuras con las que trabaja Ost para detenernos en algunos aspectos de la primera y tercera, a fin de evaluar posibles límites de esta propuesta teórica. En términos generales, sostendré que Ost hace una caracterización insuficiente de Kelsen y que el modelo Hermes es menos democrático de lo que Ost cree.

Comencemos entonces por considerar al primer modelo de juez presentado por François Ost: El juez Júpiter. Como se sabe, Júpiter es la máxima autoridad del Olimpo y es por eso elegida por Ost para caracterizar al Derecho de los Estados naciones, consolidado en el Siglo XVIII y expresado bajo la forma de Códigos. 
Júpiter representa al modelo jurídico clásico. Se trata del Derecho desarrollado en el marco del surgimiento y consolidación de los Estados naciones, unificado y sistematizado bajo la forma de Códigos. Se trata del Derecho concebido bajo la estructura de una pirámide y dispuesto de forma jerárquica. Así, el Derecho puede ser pensado como un sistema ordenado en una estructura jerárquica de normas y poderes estatales. En la cima de la pirámide, se encuentra el fundamento jurídico y político. En términos de normas, se trata de la Constitución; en términos de poderes estatales, la soberanía en manos del rey. Esta concepción del Derecho le impone al mismo una racionalidad peculiar a través de su unidad y sistematización. Las normas superiores, de carácter general, abarcan y limitan la producción de normas inferiores, haciendo que éstas estén condicionadas en su validez en función de su concordancia con las mencionadas normas superiores. Así, la estructura piramidal y jerárquica que se conforma garantiza la unidad del orden jurídico, su sistematicidad y su congruencia interna. A su vez, esta unidad y congruencia interna se corresponden con la unidad y unicidad del poder político vigente. Al interior de esta pirámide de normas, el movimiento es ascendente y descendente: ascendente en términos de búsqueda de la validez de la norma inferior; descendente en términos de creación de las normas inferiores.

Aunque Ost atribuye por igual esta concepción de lo jurídico al iusnaturalismo y al positivismo jurídico de Kelsen, yo creo que en esta equiparación se encuentran algunos problemas.

En primer lugar, hay diferencias fundamentales entre Kelsen y el iusnaturalismo racionalista moderno (que es esencialmente al que Ost parece referir aquí) al considerarlos según el modelo jupiterino. Mientras el iusnaturalismo moderno concibe un Derecho natural deducible racionalmente y estructurable en términos axiomáticos o lógicos (es decir, presuntamente se puede llegar racionalmente a primeros principios jurídico-morales a partir de los cuales deducir lógicamente el Derecho positivo y así validarlo), Kelsen (a) rechaza principios ius-filosóficos "materiales" y (b) rechaza que la relación entre normas sea de carácter "lógico deductivo". 
François Ost: de un Kelsen jupiterino a un Hermes ¿democrático?

Sobre la dinámica y la mediación. Una contraposición hegeliana

Comencemos por el punto (a) el rechazo de principios ius-filosóficos materiales. Mientras el iusnaturalismo alcanza presuntos principios racionales que establecen requisitos materiales que el Derecho positivo debe acatar (por ejemplo, ciertos derechos naturales inalienables, ciertos valores universales o ciertas doctrinas jurídicas), Kelsen sólo analiza la forma del sistema normativo y de sus componentes. Kelsen asciende hasta una hipotética norma fundamental que no posee contenido material, que no establece una doctrina jurídica positiva determinada, que no establece derechos ni valores universales (Kelsen, 2009, pp. 35, 112; Cubo Ugarte, 2021, pp. 119-120, 127, 131). En efecto, el carácter formal de su análisis es, precisamente, lo que le permite considerar a su teoría como universal, es decir, aplicable a todo Derecho positivo. Esto quiere decir que el carácter piramidal y jerárquico del sistema normativo pensado por el iusnaturalismo y el positivismo jurídico difiere: los primeros principios del iusnaturalismo racionalista establecen los valores (derechos naturales o criterios materiales) que el Derecho positivo debe acatar para ser válido, y en congruencia todos los Derechos positivos que se alejen de estos principios serán ilegítimos. Esto implica que el iusnaturalismo no sólo supone que el Derecho positivo está de alguna forma supuesto implícitamente en tales principios (esto es, que podría ser deducido o inferido de dichos principios), sino que además hay un número limitado de Derechos positivos legítimos. Es decir, el iusnaturalismo no sólo da la forma que el edificio del Derecho debe tener (i.e., la forma de la pirámide), sino que brinda además algunos de los ladrillos o bloques con los que dicho edificio debe ser conformado (por ejemplo, ciertos derechos o valores). A su vez, da un criterio para diferenciar entre "pirámides" legítimas e ilegítimas. En cambio, el modelo kelseniano sólo atiende a la mera forma de la pirámide, no determina las piezas o bloques con los cuales dicha pirámide debería ser construida, ni se sostiene que dichas piezas puedan ser deducidas de algún primer principio racional (pues la norma fundamental no es un principio racional, es una mera hipótesis formal que se postula ante el mero hecho de la eficacia del sistema normativo, Kelsen, 2015, p. 115). La propuesta de Kelsen tampoco pretende determinar cuáles "pirámides" son legítimas o ilegítimas. Todo esto nos lleva al punto (b) la relación no lógico-deductiva entre las normas. 
En el sistema jurídico pensado por el iusnaturalismo, la certeza de los principios filosófico-jurídico-morales alcanzados racionalmente y con contenido material positivo es un bien sumamente preciado. Y el sistema axiomático, garantizando la transmisión de la verdad de axiomas a teoremas, de premisas a conclusiones, brinda el mecanismo ideal para conservar y garantizar la certeza ( $y$, en congruencia, la justicia) de las normas que se han de inferir a partir de dichos principios. En otras palabras, siguiendo el modelo del sistema axiomático que tanto éxito ha exhibido en la lógica y la geometría, y confiando en que él brinda el criterio indudable de la cientificidad, el iusnaturalismo propone partir de axiomas (en este caso, no matemáticos o lógicos, sino jurídico-morales) y que el Derecho positivo sea deducido lógicamente a partir de los primeros principios mencionados. ${ }^{1}$ Así, como ocurre en la geometría en la que partir de principios verdaderos garantiza la verdad de los teoremas deducidos, en el caso del Derecho la forma axiomática garantizaría que la justicia de los axiomas se comunique a las leyes particulares. La lógica que lo rige es la lógica deductiva (capaz de esta transitividad, es decir, de comunicación del valor de verdad y, en analogía, del carácter justo).

En el caso de Kelsen, la norma fundamental no es un principio de esta naturaleza. No brinda un contenido material determinado. No establece criterios de legitimación política. No es sino un supuesto. La estructura jerárquica que se da al interior del sistema normativo no es, en sentido estricto, una estructura axiomática. La norma fundamental no brinda nada de lo que brindan los axiomas iusnaturalistas (ni Kelsen pretende que lo haga): no brinda conocimiento certero, no brinda un criterio de justicia, no brinda un contenido material (valores o derechos universales) que debiera ser acatado por el Derecho positivo. Es sólo un principio formal que supone la validez de la Constitución (ordene lo que ordene dicha constitución). Tal suposición se da ante el mero hecho de la aplicación o acatamiento de la Constitución; es la mera

\footnotetext{
1 “[E]l ideal de racionalidad matemática no era sólo de Leibniz, pues las referencias al método de los geómetras son constantes en la mayor parte de los autores iusnaturalistas de la época: Grocio, Pufendorf, Locke, Hobbes, Wolff, si bien la deducción lógica suele estar mezclada con argumentos de autoridad. La consecuencia práctica de esta actitud es la presentación axiomática del Derecho natural a través de definiciones, axiomas, reglas y leyes. El armazón teórico queda así constituido por un encadenamiento de reglas generales que derivan o se deducen las unas de las otras a partir de uno o varios principios" Ramón Martínez Tapia, 1996, p. 155.
} 
constatación de que frente al científico del Derecho se encuentra un objeto que podemos denominar "orden jurídico". En otras palabras, nada brinda certeza sobre la justicia o injusticia de lo establecido por la Constitución. Pero dicha certeza tampoco es necesaria. Kelsen describe la estructura formal de todos los ordenamientos jurídicos, más allá de lo que estos efectivamente ordenen. En congruencia con esto (y en discrepancia con el iusnaturalismo racionalista) las normas superiores no son postuladas como axiomas, no son elegidas por su certeza privilegiada: son elecciones circunstanciales de la comunidad efectivamente existente en razón de la dinámica particular de su vida política. Por su parte, las normas inferiores no se siguen por un mero acto de deducción lógica a partir de las superiores. Las normas inferiores son creaciones que introducen un nuevo contenido no completamente considerado en las normas superiores. Mientras el acto de creación que las produce respete los parámetros establecidos por las normas superiores, las normas inferiores pueden ordenar lo que sea: su contenido no está completamente determinado por las normas superiores $y$, en congruencia, no se puede simplemente deducirlas lógicamente de éstas. Tampoco sería necesario que resulten de semejante deducción lógica: la garantía de la deducción lógica es pertinente mientras se crea que las normas superiores o los principios son axiomas certeros y universalmente justos. Pero en tanto se pretenda menos de las normas superiores y se las considere simplemente bien como principios que establecen valores a articularse entre sí o bien como reglas que establecen condiciones de su aplicación, se admitirá que las normas inferiores tengan que especificar y complementar ya sea los modos de articulación de los valores establecidos en los principios (modos que no han sido especificados en las normas superiores) o ya sea la manera de ejecutar la aplicación del consecuente establecido en la regla. En congruencia con esto, las normas inferiores no pueden ni necesitan ser deducidas de las normas superiores. Para ser válidas, las normas inferiores deben respetar los parámetros materiales y formales establecidos por las superiores: iy esto es suficiente! Quiero decir, no es que las normas inferiores carecen de una certeza que 
deberían tener. Tal certeza no es posible pero tampoco es necesaria. Por tanto, las normas inferiores según Kelsen no son (ni necesitan ser) deducibles lógicamente. ${ }^{2}$

Como vemos, en contra de lo que sostiene Ost, no puede equipararse sin más los modelos iusnaturalista y kelseniano. Aunque compartan una estructura jerárquica piramidal, la lógica que los rige no es la misma, la relación que hay entre normas superiores e inferiores en uno y otro modelo es diferente. El modelo axiomático racionalista iusnaturalista supone una relación de implicación lógico-deductiva, supone principios materiales y certezas con respecto a valores y derechos universales. El modelo positivista kelseniano sólo emula una forma piramidal como resultado de la articulación de la validez de las normas, validez que no se obtiene por medio de inferencias lógicas o en función de principios materiales certeros y universales, sino por la más pedestre congruencia entre el acto creador de Derecho de la norma inferior y los parámetros generales materiales y formales establecidos en la norma superior. Yo Ilamaría a esto congruencia performativa: esto es, que el acto que pretende ser un acto creador de norma lo sea efectivamente al cumplir lo estipulado por la norma que rige tal tipo de acto. La validez no se determina de manera lógico-deductiva, con lo cual la similitud entre la forma piramidal del iusnaturalismo y la forma piramidal kelseniana es más circunstancial y menos relevante, en cierto sentido, de lo que Ost quiere hacer parecer. En lo que hace a estas diferencias se suma un tercer elemento a considerar c) la introducción de la dinámica del Derecho, otra faceta que Ost no considera.

La introducción de la consideración del carácter dinámico del Derecho en la obra de Kelsen supone un cambio de perspectiva y un problema difícil de resolver para la congruencia interna del pensamiento kelseniano. Dejando de lado esta cuestión problemática, aquí quisiera considerar lo que ella implica a la hora de contraponer el pensamiento de Kelsen con el modelo jupiterino que Ost le atribuye. El carácter

\footnotetext{
${ }^{2}$ En Kelsen se presenta el problema de hasta qué punto puede aplicarse la lógica a lo normativo. Como la norma inferior es una creación volitiva y no un mero acto de deducción intelectual, en el desarrollo de su filosofía Kelsen fue acercándose a una posición según la cual la lógica no se aplica al Derecho (Kelsen, 1979, p. 87; 2018, pp. 263 y ss.). Esta posición es, según Ferrajoli, problemática (Ferrajoli, 2017, pp. 125134, 154-156). En congruencia con Ferrajoli, creo que el problema de la (no) aplicación de la lógica al Derecho está vinculado con la tensión interna del sistema kelseniano entre estática/dinámica del Derecho, pero no puedo desarrollar esta cuestión aquí.
} 
François Ost: de un Kelsen jupiterino a un Hermes ¿democrático?

Sobre la dinámica y la mediación. Una contraposición hegeliana

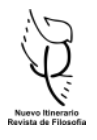

dinámico del Derecho consiste en concebir al Derecho ya no en términos de relación intrínseca entre normas estáticas, sino en términos de actos de creación del Derecho. De esta manera, dejamos de pensar al Derecho como un conjunto dado de normas para pasar a verlo como una maquinaria en funcionamiento, que actúa a través de la creación de normas y frente a la cual sólo se puede describir un estado circunstancial de dicho Derecho vigente. Al introducir el carácter dinámico del Derecho, su estructura jerárquica y la relación condicionante entre los elementos normativos que lo componen parecen invertirse. Con esto quiero decir que en la medida en que el juez o el órgano estatal de aplicación es quien crea la norma que efectivamente se aplica y en tanto sólo está sujeto en su accionar por el control ulterior que hicieran otras instancias de aplicación del Derecho, el juez se encuentra potestado para pronunciarse sobre la validez de todas las normas y sobre su significado. En tanto la interpretación efectivamente realizada es válida no en función de su relación lógico-semántica con otras normas (ni en función de algún otro tipo de relación intrínseca entre normas), sino en razón del actuar concreto de otros órganos estatales que ejercen la función de contralor sobre el acto de aplicación, la relación intrínseca entre la norma superior y la norma inferior que se denomina validez pasa a un segundo plano para ponerse en un primer plano el ejercicio efectivo de la magistratura y de los órganos de contralor que pudieran ratificar o rectificar su sentencia. En otras palabras, el carácter dinámico da primacía a la eficacia sobre la validez y supone posiblemente la inversión de la estructura piramidal: la norma superior no comunica su validez hacia abajo, sino que "lo válido" se define desde abajo, en el caso concreto, en función de las efectivas ratificaciones o rectificaciones que hacen los órganos de contralor judiciales y administrativos.

A pesar de estas diferencias fundamentales, Ost acierta al atribuir tanto al iusnaturalismo como al positivismo jurídico una lógica ascendente y descendente. Aun cuando esta lógica no sea en ambos casos indefectiblemente deductiva, se trata de un movimiento que asciende en búsqueda del fundamento y desciende en la determinación de soluciones particulares (en el caso de Kelsen, esta caracterización vale para su modelo estático). Esta lógica ascendente en la procuración de 
fundamentación y descendente en la producción de soluciones particulares está en congruencia con caracteres fundamentales del modelo jupiterino tales como el monismo jurídico y político sobre el que hablaremos más abajo. En pocas palabras, la unidad del sistema, la articulación jerárquica de las normas y la afluencia hacia un punto nodal de fundamentación conducen a la existencia de un único Derecho y una única autoridad política.

En congruencia con la caracterización que Enrique Marí (2006, pp. 177-181, 196-197) hace del Derecho tardomedieval y moderno, Ost indica que el modelo jupiterino del Derecho se caracteriza por un proceso de codificación, sistematización, unificación y simplificación que corre en paralelo con un proceso de conformación del poder centralizado del Estado nación (Ost, 2007, p. 107). Es, en términos de Ost, un reforzamiento del poder político. En razón de esto, Ost atribuye a este modelo cuatro corolarios (2007, pp. 107-108): (1) el monismo jurídico. (2) El monismo político. (3) La racionalidad deductiva y lineal. (4) La concepción del tiempo orientado hacia un futuro controlado. El primer elemento se refiere a la no diversidad de las fuentes del Derecho. El Derecho emana de una única fuente, hay un único ordenamiento jurídico, no múltiples ordenamientos jurídicos superpuestos emanados de autoridades paralelas. Frente al desorden normativo y jurisdiccional de la Europa medieval, el orden moderno se caracteriza por la unidad del sistema normativo. En congruencia con esto, el monismo político se refiere a una centralización y unificación administrativa y de la autoridad estatal, acompañada de un proceso de identificación nacional con el Estado y con su Derecho. Este proceso culmina conformando la figura del soberano, único autor del Derecho, única autoridad legítima. El tercer elemento se refiere al carácter deductivo antes considerado (con la ya indicada aclaración de que el sentido de este término puede ser disputado). Se trata del hecho de que las soluciones jurídicas particulares, es decir, aquellas que resuelven los conflictos jurídicos que surgen en el caso concreto, deben basarse en las reglas generales y éstas, en última instancia, en los principios supremos del sistema. En otras palabras, esto supone que las soluciones que ejecutan los órganos del Estado deben darse dentro del marco general estipulado por la autoridad centralizada del Estado. De lo contrario, los órganos no seguirían las 
órdenes de la autoridad central e instaurarían un orden jurídico y una autoridad política en paralelo a la de la administración centralizada del Estado nación. Es decir, el órgano de aplicación debe hacer efectiva la voluntad estatal y, por tanto, la norma creada en su decisión debe ajustarse a las pautas generales establecidas por la autoridad legitimada para crear norma jurídica. El último elemento se refiere tanto a la diferencia del Derecho moderno con respecto al Antiguo Régimen como también al control de las futuras creaciones jurídicas. En pocas palabras, el Derecho jupiterino (o quizá deba decirse de forma más genérica, la racionalidad moderna) concibe el tiempo en términos de progreso y establece las pautas generales del Derecho como un marco controlador de las decisiones jurídicas futuras: controla el progreso del orden jurídico en el tiempo, con sus indicaciones generales establece el marco general dentro del cual el orden jurídico debe desarrollarse, esto hace a la idea de "futuro controlado" (Ost, 2007, p. 108).

El segundo modelo considerado por Ost es el modelo hercúleo. El juez es representado por Hércules, semidios, el héroe de los infinitos trabajos. Se corresponde con el surgimiento del Estado benefactor de principios del siglo XX, la política económica keynesiana y el realismo jurídico de Holmes en el que el quehacer judicial es preponderante y desplaza en la caracterización del Derecho a la norma, al poder legislativo y a la noción kelseniana de validez (Ost, 2007, pp. 103, 110-1). Veamos esto.

El modelo hercúleo del Derecho se presenta como un intento de subsanar las inequidades del liberalismo económico. Como sabemos, el liberalismo político y el liberalismo económico están emparentados. Se relacionan también con una concepción del Derecho en la que prima la libertad individual (de contratar, impulsar industrias, trabajar, etc.). El foco del Derecho liberal está puesto sobre el individuo particular y sus derechos subjetivos por sobre las dinámicas que la interacción entre individuos provoca y sus efectos. Ahora bien, aun cuando el orden jurídico postula la libertad de los súbditos y su igualdad ante la ley, estas igualdad y libertad son esencialmente de carácter formal. La libertad se reduce a no tolerar la intromisión de un tercero; no se trata de garantizar medios fehacientes y positivos para la realización de los fines deseados por los particulares. Los únicos medios que el Derecho liberal 
garantiza son la supresión de cualquier acto violento no permitido que entorpezca la prosecución de los propios deseos según las reglas del mercado. Esto es, en otras palabras, la libertad está asegurada, desde el punto de vista liberal, al garantizarse la falta de coacción ilegítima. En el caso de la igualdad, se reduce nuevamente al cumplimento formal de la igualdad ante la ley. El Derecho liberal no ve en una situación de hecho de inequidad una violación al principio de igualdad. La igualdad está garantizada por la titularidad de iguales derechos con independencia de la situación de hecho de los individuos. No se trata, entonces, de una igualdad material.

El siglo XX ha mostrado que la dinámica propia de la economía puede conducir a subrayar las diferencias materiales poniendo en crisis al orden jurídico, político y económico liberal. Frente a estas inequidades y las consecuentes crisis (económicas, pero también políticas, de legitimidad), emerge el Estado benefactor que tiene a su cargo corregir las injusticias y desigualdades que surgen de manera ubicua. Esta es la tarea del juez Hércules, quien se convierte entonces en un ingeniero social con el infinito trabajo de subsanar caso por caso las injusticias del orden legal puramente formal (Ost, 2007, pp. 102, 110).

Así, el elemento fundamental del Derecho concebido desde la perspectiva hercúlea es el quehacer judicial, aun desplazando la tradicional predominancia de la norma, la validez y el poder legislativo. El legislador queda relativizado frente a la tarea jurídico-creadora del juez. A diferencia de lo que ocurre en el modelo anterior, la decisión judicial no se deriva de normas superiores de carácter general, sino que el camino que se recorre es el inverso: la decisión del caso permite inferir de manera inductiva la regla general. Es en este sentido que Ost hablará aquí de una lógica inductiva (a diferencia de la lógica deductiva que caracteriza a Júpiter) y de un movimiento ascendente que va del caso particular a la regla general. El juez Hércules también se caracteriza por aconsejar, orientar y controlar la evolución del expediente o dossier. Es un juez dúctil, adapta sus decisiones a las particularidades de la circunstancia.

Como hemos adelantado, el Derecho concebido por el modelo hercúleo supone la primacía de la eficacia sobre la validez. Aquí no es pertinente, en principio, discutir si 
François Ost: de un Kelsen jupiterino a un Hermes ¿democrático?

Sobre la dinámica y la mediación. Una contraposición hegeliana

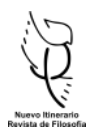

la decisión judicial es válida en razón de su correspondencia con normas superiores. Aquí prima la eficacia y se concibe al Derecho en función de la decisión efectivamente tomada por los órganos estatales de aplicación: no es primordial preguntarse por la validez de la sentencia, sino prima preguntarse si la sentencia se hará efectiva (o será rectificada o anulada por otros órganos de aplicación). Así, se invierte la pirámide que caracterizaba a Júpiter, al iusnaturalismo y a Kelsen (al menos según el modelo estático o según la lectura de Ost), para pasar a hablar aquí de un embudo o pirámide invertida (Ost, 2007, pp. 102-3, 110). El punto fundante se encuentra en el caso particular, en la decisión singular y circunstancial del juez, y de allí se eleva a la conformación de una regla general (sujeta, a su vez, a la variación de la jurisprudencia).

Esto supone la conversión del orden jurídico en una multitud dispersa de decisiones particulares, una dispersión de las autoridades que atienden a cada caso singular. Así, tenemos el Dossier, el expediente cuyas propiedades reemplazarán a las del Código y la pirámide (Ost, 2007, pp. 112-3). Frente al monismo jurídico jupiterino, contamos con (1) la proliferación de decisiones particulares. Es decir, la norma general con su abstracción característica deja de ser la protagonista del Derecho; en cambio, nos encontramos con la singularidad y la concreción del juicio realizado en el caso singular. Frente al monismo político tenemos (2) la dispersión de las autoridades. Si el monismo político jupiterino implicaba la unificación y centralidad de la autoridad administrativa, Hércules supone la dispersión y pluralidad de autoridades, tantas autoridades y tantas fuentes de Derecho como jueces y casos hay. Pluralidad de criterios de múltiples órganos estatales, haciendo a la dispersión de la presuntamente unitaria soberanía. Frente a la racionalidad deductiva de Júpiter, (3) la racionalidad inductiva que va del caso a la regla. Se trata de encontrar un resultado práctico adecuado y no de procurar la aplicación más correcta de la ley. En este sentido, el juez se apoya en su conocimiento de otras disciplinas, pues ya no se limita a ser un experto en la aplicación de reglas jurídicas, ya no es un mero representante de la voluntad suprema del soberano, se trata de un ingeniero que debe conocer y contemplar la contingencia del caso, la materialidad circunstancial y, en congruencia, considerar en su decisión factores extra-jurídicos tales como la economía, la contabilidad, la 
medicina entre otros saberes. Finalmente, frente al dominio del futuro por parte de la ley, Hércules presenta (4) un tiempo discontinuo. Lo jurídico no es un marco general normativo dentro de cuyos límites se mueve el órgano de aplicación. Lo jurídico está conformado por irrupciones jurídicas esporádicas, discontinuas y desechables. Es decir, acciones concretas del Estado representado en sus funcionarios judiciales, acciones que irrumpen, emergen en el caso, actúan de forma dispersa para el caso concreto (de manera inconexa) y una vez resuelto el conflicto se desechan y se desvanecen.

El tercer modelo de juez es Hermes, el dios mensajero. A diferencia de la pirámide y el embudo que caracterizan respectivamente a Júpiter y Hércules, Hermes es representado por la red, red jurídica por la que circula la información (Ost, 2007, p. 116) (pero podríamos pensar también en la red foucaultiana del poder). Frente al código y al dossier, Hermes posee el banco de datos (Ost, 2007, pp. 104, 121). Se trata de la tarea judicial y el Derecho propios del período postmoderno. Se corresponde con la mirada del Derecho que posee la Teoría Crítica. La naturaleza de Hermes es difícil de clasificar por su carácter móvil, líquido. Veamos un poco más de cerca en qué consiste.

El juez Hermes tiene la habilidad de ocupar tanto la función de un juez Júpiter como de un Hércules, pero se caracteriza fundamentalmente por la liquidez de la era contemporánea. Hermes concibe al Derecho como un juego (teoría lúdica que remite a Wittgenstein). Hermes interviene sobre el tablero, introduce jugadores, a fin de balancear la partida hacia el resultado deseado. Como comunicador, Hermes es la red que se extiende a través de los nodos, alcanza los elementos normativos y extranormativos, las instituciones estatales o privadas pertinentes para la resolución del caso. Es decir, el quehacer judicial no se acota a la aplicación de la ley, ni a la creación jurisprudencial. Además de estas funciones clásicas, Hermes puede introducir elementos no contemplados en el Derecho tradicional. A pesar de esto, Ost sostiene que Hermes no impide cierta previsibilidad dada por los textos jurídicos a interpretar y por las jerarquías a respetar, idea que me permitiré poner en duda más adelante.

En primer lugar, al caracterizar a Hermes, Ost habla de una multiplicidad de actores jurídicos. Hermes no está completamente encorsetado por los textos jurídicos ni por los órganos estatales destinados a la creación de normas, se mueve emulando la 
estructura de una red, acude a la base de datos e introduce en el juego operadores diversos (instituciones privadas, instituciones internacionales, etc.). Es decir, el juego jurídico se ha complejizado. Los operadores de dicho juego no son únicamente los tradicionales; Hermes va más allá, en congruencia con la concepción del Derecho propia de la Teoría Crítica: si el Derecho es una práctica social discursiva en la que se ponen en juego intereses de diversos sectores, no hay algo así como lo propiamente jurídico descontaminado de todo lo exógeno que lo rodea (a pesar de los intentos retóricos de conformar un discurso jurídico homogéneo y autónomo, Marí, 1993, p. 254). Lo jurídico es social y las operaciones "jurídicas" no son puramente jurídicas, sino también políticas, ideológicas, económicas, lingüísticas. En congruencia, la separación tajante entre operadores propiamente jurídicos (digamos, jueces, defensores, fiscales, abogados particulares) y operadores no jurídicos (ONGs, medios de comunicación, órganos supraestatales internacionales, empresas internacionales, consorcios de empresas, universidades) se desvanece o por lo menos se debilita.

En segundo lugar, Ost habla de la imbricación sistemática de funciones (Ost, 2007, p. 118). Hermes acude a distintos operadores, pero las funciones específicas de cada operador no están claramente delimitadas. Por supuesto que en el caso de los operadores tradicionales estas funciones parecen estar caracterizadas con más claridad, pero esto no es una cuestión inconmovible. Si el juez mismo puede ocupar varias funciones, y la tarea de los operadores no tradicionales no está específicamente estipulada, cabe concebir que la de los operadores tradicionales también se vea modificada. En otras palabras, el juez cumple varias funciones; no sólo dicta sentencias, sino que también propone soluciones, negocia, aconseja. Pero a la vez trae al juego a otras instituciones y elementos que no tienen una función prefijada, siendo el juez quien fija su función. Supongamos, por ejemplo, un juez que recurre a una ONG, sus estudios técnicos específicos y los protocolos por ella establecidos. Dicha ONG no es un órgano estatal ni posee, según el Derecho vigente, jurisdicción alguna. Sin embargo, el juez le da en el juego del Derecho la potestad de coadyuvar a encontrar una solución al caso en cuestión o se la pone en posición de ponderar aspectos del caso desde su saber técnico específico. Es decir, el juez introduce 
elementos y actores extra-jurídicos en la trama de lo jurídico rompiendo la tradicional ficción que separa tajantemente un terreno del otro.

El tercer elemento es la multiplicación de los niveles de poder. Así como Hermes es una red que vincula distintos nodos aparentemente desconectados y acude a documentaciones e instituciones de distinto origen para la resolución del caso, de igual modo debe hablarse del surgimiento de una multiplicidad de instancias de poder. Ya no nos encontramos únicamente con el poder centralizado estatal, contrapuesto a la sociedad civil (los súbditos) en una estructura binómica. Nos encontramos con que el Estado tiene frente a sí una pluralidad de focos de poder. Se trata desde órganos jurídicos internacionales frente a los cuales el Estado cede soberanía, como también de empresas internacionales, ONGs internacionales, laboratorios, universidades, etc. Esto se presenta en congruencia con la concepción que la Teoría Crítica posee del Derecho como una cristalización de los conflictos sociales, cristalización que se encuentra en el cruce de múltiples poderes no necesariamente estrictamente jurídicos en el sentido tradicional (Cárcova, 2009, pp. 119-120).

El cuarto elemento es la modalidad de la acción jurisdiccional. Mientras el juez Júpiter se caracteriza por el permiso, la prohibición y la obligatoriedad, el juez Hermes pretende provocar cambios en la sociedad, lo que requiere una mayor sutileza: para ello, promete, incita, planifica, disuade a través de instrumentos flexibles que no se caracterizan por la tradicional regla del Derecho (Ost, 2007, p. 119). Mientras la regla del Derecho establece una condición y su correspondiente sanción, el instrumento flexible introduce declaraciones de intención, construye pactos entre partes, anuncia planes. Esto, por un lado, permite cierta flexibilidad tanto en los modos de cumplir con los mandatos judiciales como también en las respuestas ex post facto del juez; por el otro, el instrumento flexible apunta más a la incitación, motivación y disuasión que a la mera verificación del cumplimiento/incumplimiento y su correlativa sanción.

Estas cuatro características son las que hacen que el Derecho se vuelva "líquido". La dinámica dialéctica propia de Hermes (ya no meramente deductiva ni meramente inductiva) caracteriza esta liquidez. Es la dinámica que permite pensarlo 
François Ost: de un Kelsen jupiterino a un Hermes ¿democrático?

Sobre la dinámica y la mediación. Una contraposición hegeliana

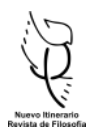

bajo la forma de red. Quisiera acentuar algunos aspectos que caracterizan a Hermes, pues me permitirán volver sobre él con una mirada crítica.

En primer lugar, quisiera señalar que la forma de red que Ost atribuye a Hermes parece remitir al pensamiento de Foucault. Como sabemos, Foucault piensa al poder en términos de red (Foucault, 1979, p. 180; 2001, pp. 36-39). El poder no se encuentra centralizado, en cabeza del rey, sino que se encuentra disperso en las instituciones que conforman al súbdito. El súbdito construido en las instituciones es lo que permite que haya un rey, un Estado centralizado, y es portador, en su cuerpo disciplinado, del poder que a la vez padece y ejerce, obedece y reproduce. El poder así concebido supone, por un lado, que no hay ausencia absoluta de poder. Quien obedece y padece el poder también está en ejercicio de cierto grado de poder, de cierta fuerza; puede optar por reproducir las relaciones de dominación o contraponerse a ellas. Por otro lado, esto supone que no hay una posición de dominio absoluto, y en congruencia no hay un centro único al cual enfrentarse con un acto revolucionario. En otras palabras, el eventual intento de cambiar las relaciones de poder al interior de la sociedad no requiere (ni tampoco podría usufructuar) un enfrentamiento monolítico contra un foco central del poder, sino que puede llevarse a cabo en pequeñas acciones, en lugares periféricos. Esto hace que el cambio social buscado no requiera disputar la totalidad del Derecho, sino que puede lograrse a través de intervenciones singulares dispersas y en casos concretos. En otras palabras, el juez puede actuar en la periferia sin necesitar para que se dé el cambio buscado una modificación integral del Derecho y del poder político centralizado. Podríamos hablar de una lógica de la resistencia periférica.

En segundo lugar, Hermes introduce en el juego del Derecho elementos que no son estrictamente normativos. Esto es especialmente interesante desde el punto de vista de la Teoría Crítica. La Teoría Crítica ha sostenido que el Derecho pretende imponer la creencia de la especificidad de su disciplina, la asepsia quirúrgica de su saber, desconectado de toda influencia política y económica. Para eso, recurre a ciertos recursos literarios que le permiten escribir el expediente conformando un discurso aparentemente homogéneo. Aunque compuesto por una diversidad de 
discursos de distinto origen, el expediente se redacta con una técnica que los introduce y los homogeneiza, conformando un discurso en apariencia uniforme.

Apoyándose en este recurso literario (o denunciándolo al exacerbarlo escandalosamente), Hermes recurre a cualquier tipo de documento o instrumento, jurídico o no, para resolver el caso. La distinción entre lo jurídico y lo no jurídico se hace borrosa. Hermes recurre a instrumentos internacionales, a informes de ONGs, a información estadística de instituciones privadas, a estudios de laboratorios o universidades. Hermes no es ya el obediente servidor del Rey, es un operador que tiene sus propios planes y por tanto no se propone expresar meramente la regla del Derecho, sin más, como repitiendo una voluntad ajena.

Ahora bien, aquí es donde se presenta uno de los puntos más problemáticos en la figura de Hermes. ¿En qué medida el ejercicio hermético de la magistratura es legítimo? ¿Qué hace legítimo a su quehacer judicial, si Hermes no expresa necesariamente la voluntad popular plasmada en el Derecho? Ante esta pregunta, Ost intenta abogar a favor de Hermes diciendo que él se sostiene en la legitimidad procedimental del Derecho (Ost, 2007, p. 125). En pocas palabras, esto significa que el quehacer judicial de Hermes es legítimo en tanto se piensa y se aplica al Derecho como procedimiento de discusión pública racional. Es decir, el Derecho se presenta como un conjunto de reglas (formales) que hacen al juego justo en tanto permiten que todos tomen la palabra. La decisión, producto resultante de la discusión racional, del juego de pedir y dar razones a favor y en contra, se encuentra así legitimada. Así, no es el más fuerte quien define el resultado del juego, pues todos participan de él, todos pueden pedir la palabra, haciendo que el juego sea democrático.

Vale aclarar que la acción jurisdiccional de Hermes no es necesariamente contra legem. Recordemos que el Derecho no se compone exclusivamente de reglas rígidas que establecen condiciones férreas frente a las cuales el órgano judicial debe dar una respuesta predeterminada, sino que también brinda principios que deben ser interpretados, matizados y puestos en relación y congruencia con otros principios. Es decir, enunciados que sostienen valores, pero no indican al juez un curso de acción preciso. Así, ya sea actuando expresa y decididamente contra legem, o ya sea 
François Ost: de un Kelsen jupiterino a un Hermes ¿democrático?

Sobre la dinámica y la mediación. Una contraposición hegeliana

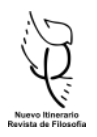

pretendiendo defender los valores establecidos en ciertos principios, el juez Hermes introduce elementos extra-normativos a fin de dar con la solución adecuada. En otras palabras, la introducción de los elementos extra-normativos no supone per se una sentencia contra legem ni una intención por parte del juez de atentar contra el orden jurídico establecido: en su ejercicio, Hermes puede creer sinceramente estar representando de manera adecuada los valores estipulados en los principios del Derecho (y en ocasiones puede tener razón) aun cuando funde su sentencia en elementos extra-normativos o desoiga lo estipulado en alguna regla del Derecho.

Sin embargo, en mi opinión, ninguna de estas salvedades es en verdad suficiente para salvar a Hermes. Temo que Hermes reemplaza al Derecho por el capricho, la voluntad popular plasmada en órganos electivos por la voluntad unilateral del juez, la construcción de la decisión a través del debate y el razonamiento públicos por la certeza moral omnisciente, inconmovible e intuitiva. En la siguiente sección me propongo desarrollar esta crítica.

\section{III- ¿Hermes o Frankenstein? El pecado hermético de la certeza intuitiva moral}

Como hemos visto en la sección anterior, Ost presenta a Hermes como una figura representativa de la democracia. El carácter democrático de Hermes está dado por dos elementos: (a) la garantía de la formalidad procesal; (b) la distribución equitativa del uso de la palabra (o en otros términos, la garantía ya no meramente formal sino material de la libertad de expresión). Estos dos elementos hacen al debate público, razonado y libre de ideas y están vinculados a lo que anteriormente hemos mencionado como la concepción lúdica del Derecho de Hermes. La concepción lúdica refería a que Hermes ve al Derecho como un juego en el que se puede introducir pluralidad de jugadores. El juez está a cargo de diagramar el tablero, determinar las movidas válidas, el tiempo de la partida, el cómputo de los puntajes, etc. De esta manera, en el juego del Derecho -atendiéndose a las garantías procesales formales y a la libertad de expresión- todos los jugadores tienen cierto grado de injerencia y participación en la producción de la sentencia. Así, a la hora de producirse la decisión 
judicial se relativiza la autoridad, el poder o la primacía que alguno de los involucrados pueda tener. Según Ost, esto hace al carácter democrático de Hermes.

Como también hemos indicado unos párrafos más arriba, vale aclarar la relación axiológica de Hermes con el sistema jurídico en función del cual él actúa. Esto es, Hermes puede posicionarse frente al Derecho como un revolucionario que pretende modificarlo desde adentro; pero esta no es la única posición posible. Hermes puede pretender representar en sus sentencias al Derecho positivo vigente y creer de buena fe hacerlo así, en la medida en que los valores del Derecho plasmados en principios constitucionales y en tratados internacionales requieren, para su realización efectiva, de la astucia y creatividad judicial. En pocas palabras, el juego del Derecho no supone necesariamente una intención maliciosa por parte del juez de desnaturalizar las prescripciones jurídicas; es esta posibilidad la que le permite a Ost creer que Hermes se mantiene dentro de los límites de lo jurídico, condición sin la cual, estimo, Ost debería conceder el carácter francamente antidemocrático de Hermes. En otras palabras, si Hermes fuera una figura que necesaria, sistemáticamente y a conciencia desvirtuara los mandatos jurídicos emanados del legislador, se requeriría de un argumento más fuerte que el alegato a las garantías formales y a la libertad de expresión para defender su carácter democrático.

Si Ost invoca el carácter democrático de Hermes, sosteniéndose en las herramientas jurídicas antes mencionadas (garantías formales procesales y la libertad de expresión), debe entenderse entonces que no piensa a Hermes como un radical adversario del Derecho que pretende hacerlo caer desde adentro. Así, según parece pensar Ost, Hermes reconoce los valores plasmados en los principios supremos del Derecho; sólo advierte que para la efectiva realización de dichos valores, se requiere de la creatividad del Dios-líquido, capaz de nivelar las interacciones jurídicas, introducir jugadores especiales, acudir a documentos extrajurídicos novedosos, etc. En tanto se den las pautas formales y materiales antes indicadas y Hermes actúe tendiente a la realización de los principios jurídicos, Ost cree que el carácter democrático de Hermes está asegurado. 
Por supuesto, esta caracterización de Hermes nos remite a una de las notas distintivas de lo jurídico desde el punto de vista de la Teoría Crítica. Se trata del carácter paradojal del Derecho. El carácter paradojal del Derecho implica que aun cuando el orden jurídico (entendido desde el punto de vista marxiano que esta escuela adopta) esté originariamente destinado a la consolidación y legitimación de relaciones de poder extrajurídicas (Foucault, 2011, pp. 77-78), tal orden jurídico puede ser utilizado para fines progresistas, a través del reconocimiento de derechos de los desposeídos y dándoles los instrumentos efectivos para su realización. Esta es, entiendo, la intención de Hermes en su concepción lúdica del Derecho. Es decir, el uso hermético del Derecho no supondría -parece creer Ost y la escuela Crítica- una radical desnaturalización del Derecho, sino antes bien la acentuación y aprovechamiento de este carácter paradojal.

Ahora bien, en mi opinión Ost pasa por alto un aspecto clave en el proceder de Hermes, un aspecto que condiciona todo lo antedicho en defensa del Dios hermético. Hermes se pone a sí mismo como contralor del proceso judicial, tanto en lo tocante a las garantías procesales como en lo que hace a la distribución -presuntamenteequitativa de la palabra en el ejercicio de la libre expresión. Hermes dirige el juego, asigna los puntos, desnivela el tablero con la introducción de nuevos documentos y jugadores, condiciona jugadas, todo esto con el fin de orientar el proceso hacia una determinada resolución del caso en cuestión. Esto quiere decir que Hermes actúa como el maestro titiritero, los jugadores parecen ser piezas del juego hermético, o al menos esta es la aspiración de Hermes (limitada y condicionada por los factores que puedan escapar de su control). ${ }^{3}$ Al menos, tal como lo presenta Ost, Hermes controla el juego (o esa sería su intención última). Esto quiere decir que Hermes sabe el resultado al que quiere llegar y actúa en congruencia con esta intención. El resultado

\footnotetext{
3 En este sentido, el texto de Duncan Kennedy Libertad y restricción en la decisión judicial: una fenomenología crítica, (1999, pp. 125, 126, ss., 129) es especialmente iluminador: el juez puede comenzar la partida sabiendo a qué resultado desea llegar, pero no tiene garantías a priori de poder alcanzar tal punto de llegada. Los factores limitantes son, por cierto, bastante pedestres: el tiempo de que dispone el juez para investigar la normativa y precedentes judiciales, la suerte a la hora de encontrar un buen argumento, la confianza fundada que el juez pueda tener en que su tarea no sea posteriormente anulada y rectificada por una instancia judicial superior (haciendo que todo su trabajo sea vano), etc.
} 
del juego jurídico no es el producto de la libre participación de los jugadores, del debate público, del juego de pedir y dar razones sólo guiado por la racionalidad. A diferencia de lo que ocurre en los juegos, se trata de una dinámica en la que quien decide la asignación de puntos y la conclusión de la partida es alguien que se encuentra, en cierto sentido y hasta cierto punto, por fuera y por arriba del juego mismo. En los juegos, el resultado de la partida se da por la interacción relativamente reglada entre jugadores; el árbitro tiene una intervención decisiva, pero no puede anular las legítimas jugadas de los jugadores sin desnaturalizar el juego en cuestión. En cambio, en el juego jurídico, la cuestión no es tan clara.

Según lo antedicho, el resultado del proceso judicial no es el producto de la interacción de los jugadores, sino el producto preestablecido de Hermes, no condicionado tanto por la jugada de cada jugador, sino por la voluntad del Dios hermético. Esto significa que dicho resultado no es el producto emergente de un intercambio legítimo, bienintencionado, sincero, orientado a la búsqueda de la justicia, sino que la partida jurídica se convierte en un mero instrumento condicionado por la meta preestablecida a la que el árbitro exógeno quiere llegar. El resultado no surge del debate y el intercambio, sino que el debate y el intercambio se construyen ad hoc en función del resultado deseado. El resultado está preestablecido por Hermes de manera inmediata e inconsulta. Hermes accede a la Justicia sin requerir mediaciones, posee un acceso inmediato a lo Justo en sí, un acceso intuitivo que le da una certeza moral inconmovible. Lo demás es un juego en el meramente humano -humano, demasiado humano- juego de dar razones.

La dinámica hermética hace la simulación de la mediación, pero en verdad carece de ella. Esta aparente mediación estaría dada por la interacción de pluralidad de jugadores y su carácter condicionante en la producción de la sentencia. Pero como hemos visto, Hermes no es un jugador, no es parte del juego. Es el Dios que rige el juego, ocupando más probablemente el lugar tradicional de Júpiter, aunque haciéndolo con cierto disimulo, con cierto revestimiento que camufle su autoritarismo (autoritarismo que no puede ya llamarse autoridad, porque la autoridad descansa en la ley inconmovible). Hermes no llega a la sentencia por medio del debate racional 
plurívoco. Hermes llega a la sentencia por un decisionismo intuicionista, una convicción moral, no perturbable por argumento alguno, que descansa en la confianza en su certeza moral inmediata y apodíctica. El juego de la argumentación es poco más que la cáscara que recubre la verdadera dinámica jurisdiccional de Hermes.

Ost pretende hacer descansar el carácter democrático de Hermes en una teoría de la argumentación (2007, p. 125). Aunque Ost no desarrolla los presupuestos de su caracterización de la democracia, parece entenderse que lo democrático se caracteriza por la posibilidad de participar en la toma de decisiones a través de la actividad reglada de dar y pedir razones. ${ }^{4}$ El resultado del proceso emerge en función de las reglas admitidas por el juego de la argumentación y en razón de la ponderación racional (según dichas reglas) de los argumentos ofrecidos. Pero la teoría de la argumentación hace a lo democrático si y sólo si la autoridad que toma la decisión final está, por un lado, condicionada por la argumentación dada y, por otro lado, sometida a alguna autoridad de contralor ulterior a la hora de determinar los criterios de admisibilidad de los argumentos (o en otras palabras, si la autoridad decisoria está verdaderamente sujetada por las reglas de admisibilidad). Aun en otras palabras, aunque el árbitro del juego no participe del juego como un jugador, debe estar, de alguna forma, sometido a su vez a ciertas reglas del juego. Pensemos, por ejemplo, en cualquiera de los cargos electivos de un Estado de Derecho en una democracia republicana: los legisladores o el jefe del ejecutivo pueden intentar hacer trampa, violar las reglas de argumentación racional, las leyes de la lógica y llegar a conclusiones irrisorias que se presenten en sus resoluciones como debidamente justificadas. Pero el electorado tendrá la última palabra, inexorable. Hermes, en cambio, permite el debate libre, pero asigna los puntos sin tener que responder a una legalidad que lo conmine; establece los criterios de admisibilidad de los argumentos sin tener que responder (en principio) ante nadie. ¿Qué garantiza que el juego de la argumentación, el debate público, sea justo y democrático, si la autoridad no está sometida a su vez a parámetros legales previos?

Este es el problema central con el modelo hermético de la magistratura. La intuición moral se complementa con un revestimiento de argumentación, debate,

\footnotetext{
${ }^{4}$ Sobre la relación entre democracia y argumentación, véase Barreyro 2017.
} 
pluralidad y racionalidad. Pero la sentencia carece de mediación; no emerge de la articulación de jugadas claramente regladas; emerge de manera espontánea de la mera decisión unilateral de Hermes y se la recubre ad hoc con una apariencia dialógica. La autoridad de Hermes no se somete, en principio, a una ulterior legalidad o contralor (o en todo caso, no se somete a un contralor cuyo carácter democrático, racional y plural esté garantizado de manera más satisfactoria que aquella que se atribuye al propio Hermes; se somete, únicamente, a un contralor que bien puede ser otro Hermes). En tanto las autoridades judiciales no son elegidas de manera periódica ni por elección directa (lo que por otra parte puede ser un acierto) y en tanto Hermes puede alejarse de la norma escrita dada por el Legislador (electo), cabe preguntarse en dónde radica su carácter democrático.

Como se advierte, mi mirada sobre Hermes es crítica. No critico sus buenas intenciones de subsanar las posibles insuficiencias del orden social vigente, sino que critico su confianza no contrastada en su omnipotencia y omnisciencia moral. El principal defecto de Hermes es que cree saber inmediatamente qué es lo Justo y cree representar sin más a la población (o al Derecho, que responde a la población), cuando los funcionarios judiciales no pueden invocar a favor de tal presunta representación un acto electoral ni pueden acreditarla con la ratificación o el refrendo popular a posteriori por medio un procedimiento formal y empíricamente verificable. Si se me permite dar una opinión, diré que es un acierto que jueces y fiscales no sean electos de forma directa. En tanto su compromiso debe ser únicamente con el imperio de la ley, requieren de toda la protección que pueda dárseles. De lo contrario, el temor a la represalia de los poderosos o la necesidad de congraciarse con las mayorías podría comprometerlos a actos de injusticia o al avasallamiento de los derechos de minorías electoralmente poco significativas. Pero la más alta protección se encuentra supeditada al imperio de la ley. La protección suprema que jueces y fiscales merecen descansa sobre el supuesto de que estos representen a la ley, sólo a la ley y a nada más que la ley (sobre todo en un Estado de Derecho, republicano y democrático). El imperio de la ley posee un cariz democrático en tanto se trata del imperio de la voluntad popular mediada por las instituciones políticas de un Estado de Derecho. Si el 
juez se desliga del Derecho producido por la comunidad, ¿̇en qué consiste el carácter democrático de su función o de su sentencia? Si no fue electo, ni aplica el Derecho dictado por los representantes del pueblo, o se aleja de la clara regla del Derecho para dar prevalencia a difusos principios de contenido impreciso, completados por actos interpretativos volitivos personales cuya corrección es difícil de constatar, ¿en qué puede basar su presunto carácter democrático?

Creo que gran parte del dilema hermético se encuentra en la última frase del párrafo anterior: Hermes puede invocar alejarse de la regla jurídica en pos de la aplicación de un principio jurídico superior no reglado, que requiera de una mayor ponderación e interpretación. Lo cierto es que Hermes puede, de buena fe, creer estar aplicando el Derecho vigente cuando desoye ciertas reglas claramente establecidas por el legislador. Pero es aquí donde se impone el punto crítico antes señalado. Hermes confía en su certeza moral, Hermes confía ciegamente en su intuición moral. Hermes cree que accede inmediatamente al conocimiento de lo Justo (sea esto lo que él cree encontrar dispuesto en ciertos principios imprecisos o en algún elemento que excede al orden jurídico positivo). Como el resultante del proceso judicial regido por Hermes no se da por la mediación de jugadores, ni se encuentra estrictamente fundado en documentos de cariz claramente jurídico, sino que la mediación de los jugadores está preestablecida y premeditada de manera meramente utilitaria en razón del resultante deseado y en tanto el uso de documentos jurídicos y extrajurídicos parece a Hermes equivalente, tal producto descansa únicamente en la intuición apodíctica moral que Hermes cree tener.

Es precisamente en este sentido que Hegel puede ser un contrapunto pertinente para pensar los límites e insuficiencias de Hermes. Si Hermes se caracteriza por la inmediatez y la intuición, el filósofo de la dialéctica es quien nos recuerda la necesidad de la mediación. Vale señalar que Ost $(2007$, pp. 105,122$)$ atribuye a la escuela crítica caracterizada por Hermes la dialéctica y la paradoja. Pero lo cierto es que Ost parece olvidar que la dialéctica se caracteriza por la mediación y la negación. Es decir, el movimiento dialéctico es una manera de vincular elementos aparentemente autónomos y supone un enriquecimiento del punto de partida a través 
de un movimiento de negación interna. En otras palabras, la dialéctica es lo contrario de la intuición inmediata sobre la que Hermes se sostiene.

Aunque aquí no me propongo reconstruir la filosofía jurídico-política de Hegel, vale concluir haciendo una breve referencia a la necesidad de mediación en dicho terreno. En su juventud (Kroner, 1981, pp. 19, 21) Hegel había intentado recurrir a un modelo político caracterizado por la inmediatez para dar respuesta a sus inquietudes. Hegel había tomado a la comunidad griega como el modelo idílico de lo político. Pero este modelo será desplazado en su primera gran obra, la Fenomenología del espíritu. ¿En qué se basa el entusiasmo de Hegel por la comunidad griega y por qué en la Fenomenología esta figura es sobrepasada por otras? En pocas palabras, la comunidad griega muestra una inserción inmediata y profunda del individuo en la comunidad. El individuo de la polis está profundamente sumergido en la vida cultural de su comunidad, sin espacio para el distanciamiento reflexivo. El individuo está inmerso en las creencias y prácticas culturales y religiosas de su comunidad. No toma distancia, no las cuestiona, no las articula por medio de la reflexión. De esta manera, el modelo griego puede ser una respuesta a varias problemáticas. Por un lado, supondría una respuesta a la pregunta que Hermes parece formular, la pregunta por el Derecho vigente: el juez debe aplicar el Derecho que todos reconocen, el Derecho de la comunidad, no otra cosa. Pero el modelo griego puede ser visto también como una solución al problema de la modernidad.

El problema de la modernidad es la progresiva pérdida de la articulación orgánica de la comunidad. En otras palabras, la sociedad moderna ya no se ve articulada por un modo de vida común, sino que se articula por el pensamiento utilitario y pragmático. La articulación de las partes que conforman el todo comunitario se da a través del trabajo y la producción, para los cuales el cálculo utilitario es fundamental. El intercambio y el mercado son el medio a través del cual pervive la vinculación de las partes. Frente a este factor cohesivo meramente utilitario, la comunidad griega parece ofrecer una vitalidad inherente de otro origen, brindando un Estado orgánico, imbricado con las íntimas creencias y modos de vida de su población. 
François Ost: de un Kelsen jupiterino a un Hermes ¿democrático?

Sobre la dinámica y la mediación. Una contraposición hegeliana

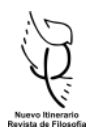

Ahora bien, en la Fenomenología del espíritu la figura que se corresponde con la vida comunitaria de la polis es la sustancia ética con la que comienza el sexto capítulo "El espíritu". Pero esta figura exhibe prontamente sus insuficiencias con el drama de Antígona, la necesidad del reconocimiento de los derechos individuales y la consecuente emergencia del Derecho romano y la noción de persona (Hegel, 2010, pp. 557 y ss., 567 y ss.). Es decir, el autor de la Fenomenología retoma su mirada idílica sobre Grecia, pero reconoce sus límites y no teme superarla. El tratamiento fenomenológico de Grecia es la respuesta madura de Hegel a sus propios ideales de la temprana juventud. La comunidad política que Hegel pensará unos años más tarde en su Filosofía del Derecho se caracterizará, precisamente, por la noción de mediación, por la articulación de las voluntades individuales a través de la mediación institucional que construye una voluntad particular tendiente a vincularse con el todo (Hegel, 2004, pp. 222-3, 225; Assalone, pp. 129, 139). En otras palabras, la modernidad no puede recuperar la unidad griega carente de mediación y de reflexión. Pero puede construir una nueva unidad no meramente utilitaria a través de la mediación de voluntades.

La pretendida virtud de la mediación hegeliana en la esfera jurídico-política radica en que Hegel espera que ésta permita una articulación de las voluntades singulares a través de instituciones que construyen una voluntad particular y logran, a fin de cuentas, la articulación en una voluntad universal. En otras palabras, es la mediación y no la inmediatez la que logra la construcción de un Derecho y un orden político orgánico y concordante con el modo de vida e intereses de los miembros de la comunidad. A través de las instituciones mediadoras, los individuos logran su reconocimiento y su representación, su participación mediata sobre la creación del Derecho. Esto hace innecesario que un funcionario aislado capte la verdad y lo justo de manera inmediata y por medio de una intuición intelectual incapaz de justificación dialógica y racional, porque lo justo (o al menos, lo justo para esa comunidad) ya está volcado en el Derecho conformado o, en todo caso, se está volcando en el Derecho que se está conformando. En otras palabras, la mediación en la esfera político-jurídica es la solución para la conformación de un Derecho democrático (entendido como concordante con los valores de la comunidad) y esto hace innecesario que el 
funcionario judicial recurra a decisiones absolutamente novedosas, sorprendentes, inesperadas. No debe entenderse por esto que el pensamiento jurídico de Hegel es conservador. La innovación jurídica es admitida y no supone un obstáculo a su carácter democrático, pero debe emerger como parte del desarrollo de la vida comunitaria y de su cultura, no como la imposición formal y unilateral de un átomo político aislado. En otras palabras, la comunidad, los pueblos y su cultura son dinámicos. Esto supone la apertura del curso de la historia y la admisibilidad del cambio político y jurídico. Pero la instauración unilateral de un orden jurídico discordante con la cultura de la comunidad por parte de un funcionario desconectado del modo de vida efectivo de dicha comunidad no es parte de la dinámica que provocará cambios provechosos y perdurables, sino que se parece más a una imposición sin representación.

Aun cuando Hegel no es un pensador de la democracia, su modelo de lo jurídico-político parece más democrático que la propuesta de Ost. La construcción de lo jurídico a través de la mediación cumple con lo que Ost prometía pero no brindaba. Lo normativo, en Hegel, se construye, es el resultado de una dinámica que no puede instaurarse (perpetuamente) de manera unilateral. Lo unilateral, lo parcial, indefectiblemente caerá. La concepción normativa de Hegel permite que el Derecho se enriquezca con la vida y experiencia comunitarias, con los cambios circunstanciales, con todo aquello con lo que la comunidad aprende. La mediación hegeliana le da al todo un cierto margen de movilidad. La comunidad, su cultura y su normatividad no es un todo monolítico que, frente a la más mínima rajadura, colapsa por su titánico peso. Al ser un todo viviente de partes vivas y articuladas, tolera variaciones de distinta importancia. Está abierto a cambios progresivos significativos de mayor o menor medida. Está abierto al devenir histórico, al desarrollo de la cultura y tolera la interacción dinámica y dialéctico-especulativa con factores históricamente dinámicos como la cultura, los valores, las creencias, la religión, la economía, las guerras, etc. Lo normativo no depende de lo que un juez en su aislamiento imagine justo o beneficioso. Las normas no emergen de la acción del juez, guiada por la intuición incomunicable, basada en elementos no normativos que él elige caprichosamente. La fuente hegeliana de normatividad emana de las prácticas efectivas de los subgrupos 
François Ost: de un Kelsen jupiterino a un Hermes ¿democrático?

Sobre la dinámica y la mediación. Una contraposición hegeliana

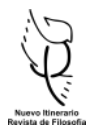

comunitarios, con lo cual tienen cierto grado de arraigo en la comunidad, aceptación y existencia efectiva. Es decir, si el juez hermético quiere recurrir a elementos potencialmente normativos (o posiblemente entendidos como normativos aunque no necesariamente jurídicos), no necesita hacer otra cosa que recurrir a las pautas ya vivientes en la comunidad, en los subgrupos. Recurrir a los momentos de mediación de las instancias particulares de la comunidad. Hacer esto no supone atentar contra el carácter democrático del Derecho, siempre y cuando el juez reconozca como parámetro externo y prioritario a la normatividad invocada y no se trate de un mero juego retórico construido ad hoc.

En razón de sus insuficiencias, Hermes no es la instauración de la democracia, sino más probablemente la instauración del capricho. El juez-capricho que se convierte en Rey. Hermes no advierte los efectos inesperados de sus invenciones y no duda de su subjetiva certeza moral. No sometido al plebiscito ni al sufragio, nada lo desmiente, nada lo somete a la potencial refutación. El juez debe desconfiar de su intuición moral, debe recurrir a lo que se hace y buscar pautas objetivas de normatividad. De lo contrario, Hermes enajenará los tribunales. Serán el terreno de una normatividad extraña a la comunidad. La lógica de la novedad, el azar de cada caso. Hermes es Frankenstein. Es la soberbia del inventor que no puede predecir los efectos de su invención y que no duda de la certeza moral que lo guía; es la horrorosa creación bienintencionada. La autoritaria extravagancia de un júpiter (con j minúscula) de un olimpo muy pequeño. 


\section{Bibliografía}

Assalone, E. (2018). La mediación ética en la esfera privada de la Filosofía del Derecho hegeliana. Tópicos. Revista de Filosofía (55), pp. 127-162. DOI: http://dx.doi.org/ 10.21555/top.v0i55.909

Barreyro, M. E. (2017). La legitimación democrático-deliberativa del Derecho. Investigación de sus fundamentos ácratas. Buenos Aires: La Ley.

Cubo Ugarte, O. (2021). Kant y Kelsen: sobre la temporalidad del derecho positivo. En: Manuel A. Bermejo Castrillo (ed.), Temporalidades Inter Disciplinares. (Derecho, Filosofía, Política) (pp. 117-141). Madrid: Dykinson.

Ferrajoli, L. (2017). La lógica del Derecho. Diez aporías en la obra de Hans Kelsen. (Perfecto Andrés Ibáñez, trad.). Madrid: Trotta.

Foucault, M. (1979). Microfísica del poder (Julia Varela y Fernando Alvarez-Uría, trad.). Madrid: Las Ediciones de La Piqueta.

Foucault, M. (2001). Defender la sociedad. Buenos Aires: Fondo de Cultura Económica. Foucault, M. (2011). La verdad y las formas jurídicas. (Enrique Linch, trad.). Barcelona: Gedisa.

Hegel, G. W. F. (2004). Principios de la filosofía del derecho (Juan Luis Vermal, trad.). Buenos Aires: Sudamericana.

Hegel, G. W. F. (2010). Fenomenología del espíritu (Antonio Gómez Ramos, trad.). Madrid: ABADA Editores/UAM.

Kelsen, H. (1979). Teoría pura del derecho. (Roberto Vernengo, trad.). México: UNAM.

Kelsen, H. (2015). Teoría pura del derecho (Moisés Nilve, trad.). Buenos Aires: Eudeba.

Kelsen, H. (2018). Teoría general de las normas. (Miguel Ángel Rodilla, trad.). Madrid: Marcial Pons.

Kennedy, D. (1999). Libertad y restricción en la decisión judicial: una fenomenología crítica. Bogotá: Universidad de los Andes.

Kroner, R. (1981). El desarrollo filosófico de Hegel (Alfredo Llanos, trad.). Buenos Aires: Leviatán. 
Marí, E. (1993). "Moi, Pierre Riviere" Y el mito de la uniformidad semántica de las ciencias jurídicas y sociales. En: Enrique Marí, Papeles de filosofía (pp. 249290). Buenos Aires: Biblos.

Marí, E. (2006). La interpretación de la ley. Análisis histórico de la escuela exegética y su nexo con el proceso codificatorio de la modernidad. En: Enrique Marí, Cárcova, Carlos M., et alii (ed.), Materiales para una teoría crítica del Derecho (pp. 163-207). Buenos Aires: Abeledo-Perrot.

Martínez Tapia, R. (1996). Leibniz y la ciencia jurídica. Anales de Derecho, N¹4, pp. 149-176.

Ost, F. (2007). Jupiter, Hércules, Hermes: tres modelos de juez. Academia. Revista sobre la enseñanza del Derecho, año 4, nº, pp. 101-130. 